\title{
Bioethics for peace and sustainable development of Bangladesh
}

\author{
Shamima Parvin Lasker ${ }^{1}$ Md morshadur Rahman ${ }^{2}$ \\ 1. Professor \& Head of Anatomy MH Samorita Medical College, Dhaka and Secretary General , \\ Bangladesh Bioethics Society \\ 2. Senior Reporter, Bangladesh Sangbad Sangstha
}

\begin{abstract}
Bioethics is a vital part of a sustainable development. In this paper we discuss why developed country incorporate bioethics along with development of science and technology; and why bioethics decision-making is important to long term development of Bangladesh.
\end{abstract}

Introduction: For the past 20 years, Bangladesh has made significant progress in several major areas of human development. Some of the indices increase the score of Human Development Index (HDI), e.g., life expectancy, literacy rate and nutritional status. Life expectancy and literacy rate are higher in Bangladesh than the neighboring counties such as India and Pakistan. A report says that nutritional status of under five year children in Bangladesh has increased and is stood second position after Sri Lanka among South East Asia region. In contrast, the economic development of Bangladesh remained much below that of many developing countries in the area. One of the main reasons for less than expected economic growth is the lack of good governance and ethical practices. Since the 1990s, a global discourse has been growing that ethical education is vital for the improvement of governance and development in developing countries. The need for ethical education has been emphasized by almost all international organizations and the members of the international assistance community.

Meaning of Bioethics: Ethics means moral value, norm and attitude. It is the understanding of human behavior in relation to values. It determines which behaviors are good and acceptable and which are bad. Bioethics is the understanding of right, responsibility, justices and moral interaction with the living being. The simplest way of defining bioethics is ethical issue raised by questions involving life (bio) in every day living. As for example: What food should we eat? How is food grown? Where should I live? How much disturbance of nature should I make? What relationship should I have with fellow organism, including human being? How do we balance the quality of our life?

Bioethics is based on four basic principles, e.g. a. Respect of person, b. Beneficience, c. Non Malficience, and d. Justice. Bioethics teaches how to balance between different benefits, risks and duties. It includes medical ethics, environmental ethics and ethics in science, business, law, social science and decision making. Concepts of bioethics can be seen in literature, art, music, culture, philosophy and religion. Bioethics can be use as synonyms of professional ethics. Now a day bioethics has gained immense important in whole of the 
world due to rapid advancement in science and technology, drastic changes in macroeconomic planning and globalization.

Discussion: Though bioethics has existed in every religion and in every region through out the ages but in the 1970s it emerged as a discipline of academic in USA due to the increasing complexity of medical advances. Van R Potter proposed the theory of bioethics for preventing possible threats to the accepted principles of equity and social justice in life especially in human. Since its inception, the field has grown exponentially in its scope and importance. Today, there are bioethics departments in over 60 U.S. academic medical centers. Many hospitals are now employing bioethics experts to guide on such issues as allocation of scarce resources, how to care for terminally ill patients and dilemmas of doctors facing everyday for advancement of new technology. There are at over $95 \%$ of U.S. hospitals has ethics committees for helping physicians, nurses and families on bioethical issues on a case-by-case basis. Thus today bioethics is not only a reasoned discourse but a matter of crisis management.

UNESCO, a leading agency of United Nation addresses the ethical issue on recent advancement in sciencs and technology. The Regional Unit for Social and Human Science (RUSHAP) of UNESCO is working in Asia-Pacific Region on ethics of science and technology. In Bangladesh, UNESCO Dhaka in partnership with the RUSHAP and with the enterprise of Prof. Shamima P Lasker and Dr Arif Hossain took initiative to support the constitution of the first ever Bioethics Society in Bangladesh. As a result, Bangladesh Bioethics Society (BBS) was established in 2009 that was launched by H.E. Nurul Islam Nahid, former Minister for Education, People Republic of Bangladesh. Over the last couple of years BBS has organized a number of seminars and workshops, courses and international conference to familiarize the idea of bioethics and encourage the research on bioethics issues in Bangladesh.

Bangladesh is a pluralistic society with a wonderful diversity of values and ethical ideals. But poverty, natural calamites, lack of proper and substantial education and rapidly advancing technology people are forced to deal with one crisis after another. Rapid growth in population has put a tremendous pressure on the resources needed to meet the basic needs of the people such as food, housing, education and health. In a result bio-ethical decision, sanctity of life is deemed to be less important than the quality of life. People are forgetting to reason soundly and coherently. Corruption, nepotism, selfishness, misconduct and malpractice are becoming the common phenomena in Bangladesh. It gives the impression that we don't able to tell which values need to be employed when and which ethical dilemmas need our most immediate attention in our society. As a result, morality and ethics are defeated by the greed. We are living through a time as if material gains take precedence over righteousness. Actually, there is huge gap in teaching of ethics in all level to coup with recent development human mind and psychology with the advance of science and technology. 
Ethicists carefully and critically explore how we think and determine right and wrong. They investigate what motivations that govern personal and group action. Ethics forms the basis of almost all personal decision-making, whether we are aware of it or not. The same is true of decision-making in professional life, including business, law, and medicine; in civil and political life and in questions of social justice. In reality, deficiency in proper and substantial moral education and lack of practice of ethics in society corruption, nepotism, selfishness, misconduct and malpractice are becoming the common phenomena in Bangladesh.

Bangladesh achieved independence in 1971 under the leadership of the Father of the Nation, Bangabandhu Sheikh Mujibur Rahman through a historic struggle and a nine-month-long war of liberation. The driving force behind the struggle was the dream for a happy, prosperous peaceful and harmonious society. But, during the last forty-four years, this dream was thwarted. Different laws, rules, regulations, policies, and a number of organizations are established by the Governments to curb the corruption for free from hunger, illiteracy, unemployment, deprivation and poverty. But nothing is improved the condition of Bangladesh rather then holding championship in corruption thrice in 1990s. However, present Prime Minister, daughter of Banglabandhu Sheikh Hasina recently understand that enforcement of law and punishment may not the suffice to eradicate corruption. She realized that a movement has to be launched to prevent corruption, exploitation to ensure human rights and freedom, equality and justice for the citizens. She recognized that the behavioral excellence influenced by ethics, morality and honesty can make a society free from corruption and good governance. Therefore, she has taken National Integrity Strategy under Vision 2021 to encourage the culture of ethics and morality among the people in the society.

Conclusion: Bioethics education may change the people's outlook in the society. To establish a happy, prosperous and peaceful society by changing the people's mindset is a great challenging. Hope Prime Minister, Sheikh Hasina can establish ethics and fulfill the dream of Banglabandhu's Sonar Bangla and make Bangladesh free from hunger, illiteracy, unemployment, deprivation and poverty.

Author Contribution: $1^{\text {st }}$ author evolved the idea $\&$ wrote the $1^{\text {st }}$ draft. $2^{\text {nd }}$ author flourish the idea further and meticulously draft the manuscript.

Conflict of Interest: There is no conflict of interest to declare. 